\title{
Effect of different starting materials on the synthesis of $\mathrm{Ba}_{0.8} \mathrm{Ca}_{0.2} \mathrm{TiO}_{3}$
}

\author{
P. N. MEDEIROS ${ }^{a}$, V. D. ARAÚJO ${ }^{b}$, A. P. A. MARQUES ${ }^{c}$, \\ R. L. TRANQUILIN ${ }^{a}$, C. A. PASKOCIMAS ${ }^{a}$, M. R. D. BOMIO ${ }^{a}$, \\ J. A. VARELA ${ }^{d}$, E. LONGO $^{d}$, F. V. MOTTA ${ }^{a, *}$ \\ ${ }^{a}$ DEMAT, CT, UFRN, Av. Sen. Salgado Filho, 3000, CEP 59072-970 Natal, RN, Brazil \\ ${ }^{b}$ UACSA, UFRPE, BR 101 Sul, 5225, CEP 54510-000 Cabo de Santo Agostinho, PE, Brazil \\ ${ }^{c}$ UNIFESP, Rua Prof. Artur Riedel, 275, CEP 09972-270 Diadema, SP, Brazil \\ ${ }^{d}$ LIEC, IQ, UNESP, Rua Francisco Degni s/n, CEP 14801-907 Araraquara, SP, Brazil
}

Received: September 14, 2014; Revised: October 28, 2014; Accepted: October 29, 2014

(c) The Author(s) 2015. This article is published with open access at Springerlink.com

\begin{abstract}
Literature has reported the synthesis of barium calcium titanates by various synthesis methods such as solid state reaction, co-precipitation and polymer precursors. These compounds are usually obtained using calcium carbonate $\left(\mathrm{CaCO}_{3}\right)$, barium carbonate $\left(\mathrm{BaCO}_{3}\right)$ and titanium oxide as starting materials. This study investigated the effect of different starting reagents on the synthesis of $\mathrm{Ba}_{0.8} \mathrm{Ca}_{0.2} \mathrm{TiO}_{3}$ (BCT) by complex polymerization method (CPM). Two sets of starting precursors were used: titanium citrate, $\mathrm{CaCO}_{3}$ and $\mathrm{BaCO}_{3}$, and titanium citrate and $\mathrm{Ba}_{1-x} \mathrm{Ca}_{x} \mathrm{CO}_{3}$ solid solution precursor. Samples were crystallized at a temperature range from $400{ }^{\circ} \mathrm{C}$ to $700{ }^{\circ} \mathrm{C}$ for different time. The obtained powders were characterized by X-ray diffraction (XRD), thermogravimetry (TG) and differential thermal analysis (DTA), and Raman and infrared spectroscopy. The infrared spectroscopy indicated that the chelation processes of $\mathrm{Ba}, \mathrm{Ca}, \mathrm{Ti}$ and $\mathrm{CA}$ ions are very similar. The results showed that the use of $\mathrm{CaCO}_{3}$ and $\mathrm{BaCO}_{3}$ or $\mathrm{Ba}_{1-x} \mathrm{Ca}_{x} \mathrm{CO}_{3}$ solid solution as precursors does not affect the final properties of $\mathrm{BCT}$ powders obtained by CPM.
\end{abstract}

Keywords: ceramic; synthesis; $\mathrm{Ba}_{0.8} \mathrm{Ca}_{0.2} \mathrm{TiO}_{3}$ (BCT); complex polymerization method (CPM)

\section{Introduction}

Ceramic materials based on $\mathrm{BaTiO}_{3}$ (BT) exhibit tetragonal phase with ferroelectric, piezoelectric and thermoelectric properties at room temperature $[1,2]$. However, BT presents an endothermic transition at $129.6{ }^{\circ} \mathrm{C}$ that corresponds to the tetragonal to cubic phase transition at the Curie temperature $[3,4]$. With the aim of increasing the Curie point, modifiers of the barium titanate network can be added. A metal that has

\footnotetext{
* Corresponding author.

E-mail: fabiana@ct.ufrn.br
}

been studied as BT modifier is calcium, which forms barium calcium titanate $\mathrm{Ba}_{1-x} \mathrm{Ca}_{x} \mathrm{TiO}_{3}(\mathrm{BCT})$ [5]. BCT, with similar behavior to $\mathrm{BT}$, is a ferroelectric material at room temperature and increases the stability of the tetragonal phase [6-8].

It can be found in the literature a variety of chemical routes used to obtain BT ceramics, such as Pechini precursor route $[9,10]$, hydrothermal [11-13], sol-crystal method [14], carbonate-oxalate (COBCT), gel-carbonate (GCBCT) and gel-to-crystallite conversion (GHBCT) [15] and low-temperature direct synthesis (LTDS) [16]. Tiwari et al. [17-19] synthesized BCT via solid state reaction using 
$\mathrm{Ba}_{0.9} \mathrm{Ca}_{0.1} \mathrm{CO}_{3}$ solid solution and titanium oxide $\left(\mathrm{TiO}_{2}\right)$ as starting materials. $\mathrm{Ba}_{0.9} \mathrm{Ca}_{0.1} \mathrm{CO}_{3}$ was obtained by co-precipitation of barium and calcium chlorides using ammonium carbonate. The authors observed higher calcium stoichiometric homogeneity in powders synthesized from mixed carbonate than in preparations using barium $\left(\mathrm{BaCO}_{3}\right)$ and calcium carbonates $\left(\mathrm{CaCO}_{3}\right)$.

This study investigated the effect of using different starting materials on the synthesis of barium calcium titanate by complex polymerization method (CPM) in order to evaluate possible differences in the stability of the polymer resins and the formation of additional phases in calcined BCT powders. Two sets of starting precursors were used: titanium citrate, $\mathrm{CaCO}_{3}$ and $\mathrm{BaCO}_{3}$, and titanium citrate and $\mathrm{Ba}_{1-x} \mathrm{Ca}_{x} \mathrm{CO}_{3}$ solid solution precursor.

\section{Experimental}

BCT powders were prepared by complex polymerization method (CPM). The reagents used were titanium isopropoxide(IV) ([Ti[ $\left.\mathrm{OCH}\left(\mathrm{CH}_{3}\right)_{2}\right]_{4}$, Aldrich, 97\%), calcium carbonate $\left(\mathrm{CaCO}_{3}\right.$, Aldrich, $99 \%$ ), barium carbonate $\left(\mathrm{BaCO}_{3}\right.$, Mallinckrodt, $\left.99 \%\right)$, calcium chloride dehydrate $\left(\mathrm{CaCl}_{2} \cdot 2 \mathrm{H}_{2} \mathrm{O}\right.$, Merck, $99.5 \%$ ), barium chloride dehydrate $\left(\mathrm{BaCl}_{2} \cdot 2 \mathrm{H}_{2} \mathrm{O}\right.$, Mallinckrodt, $99.9 \%$ ), ammonium carbonate $\left(\mathrm{NH}_{4} \mathrm{CO}_{3}\right.$, Mallinckrodt), citric acid $\left(\mathrm{H}_{3} \mathrm{C}_{6} \mathrm{H}_{5} \mathrm{O}_{7}\right.$, Merck, $\left.99.5 \%\right)$, ethylene glycol $\left(\mathrm{HOCH}_{2} \mathrm{CH}_{2} \mathrm{OH}\right.$, J.T. Baker, $\left.99 \%\right)$ and ammonium hydroxide $\left(\mathrm{NH}_{4} \mathrm{OH}\right.$, Merck, $\left.99 \%\right)$.

Titanium citrate (TC) aqueous solution precursor was prepared using titanium isopropoxide(IV) (Ti) and citric acid (CA) in a molar ratio of Ti:CA=1:4. For the synthesis of $\mathrm{BCT}$ resins, $\mathrm{Ba}^{2+}$ and $\mathrm{Ca}^{2+}$ cations were added to the titanium citrate solution. In the first set, the cation sources were $\mathrm{CaCO}_{3}$ and $\mathrm{BaCO}_{3}$, and for the second set, the cation source was $\mathrm{Ba}_{1-x} \mathrm{Ca}_{x} \mathrm{CO}_{3}$ which was obtained by co-precipitation of barium and calcium chlorides by ammonium carbonate as shown elsewhere [20]. After the addition of cations, $\mathrm{pH}$ was adjusted to 7-8 with ammonium hydroxide, and ethylene glycol was added to the solution which was remained at a temperature of about $80{ }^{\circ} \mathrm{C}$ under stirring to promote the polyesterification reaction and the evaporation of excess water.

For the production of BCT ceramic powders, polymeric resins obtained were submitted to thermal treatment at $300{ }^{\circ} \mathrm{C}$ for $4 \mathrm{~h}$ at a heating rate of
$10{ }^{\circ} \mathrm{C} / \mathrm{min}$ to promote the pyrolysis of organic compounds. After this treatment, the obtained material was separated and then calcined in a temperature range of $400-700{ }^{\circ} \mathrm{C}$ at a heating rate of $5{ }^{\circ} \mathrm{C} / \mathrm{min}$, for different time from $1 \mathrm{~h}$ to $8 \mathrm{~h}$.

Precursor solutions and calcined powders were both characterized. Characterizations were performed by $\mathrm{X}$-ray diffraction (XRD) using a Rigaku diffractometer (Model $\mathrm{D} / \max -2500 / \mathrm{PC}$ ) with $\mathrm{Cu} \mathrm{K} \alpha$ radiation in order to analyze the crystalline phases in the samples. Infrared spectroscopy was conducted using Bruker Equinox $/ 55$ spectrophotometer in the $400-4000 \mathrm{~cm}^{-1}$ region at room temperature. Thermogravimetry (TG) and differential thermal analysis (DTA) were conducted using a TA Instruments machine under oxygen flow $\left(100 \mathrm{~cm}^{3} / \mathrm{min}\right)$ and subjected to heating rate of $5{ }^{\circ} \mathrm{C} / \mathrm{min}$ from room temperature to $900{ }^{\circ} \mathrm{C}$ in order to estimate the temperature range in which phase changes occurred. Raman spectroscopy was conducted using Bruker RFS100 spectrophotometer, with Nd-YAG laser (1064 nm) as excitation source (power of $23 \mathrm{~mW}$ with 100 scans and resolution of $4 \mathrm{~cm}^{-1}$ ).

\section{Results and discussion}

Analyses performed by infrared spectroscopy indicate the formation of complexes of metal ions $(\mathrm{Ba}, \mathrm{Ca}$ and Ti) with citric acid (CA), even before the addition of ethylene glycol. Figure 1 shows the infrared spectra of titanium citrate (TC) and precursor solutions before polymerization by ethylene glycol. The results indicate similar spectra for solutions using different starting reagents. It could be seen that the spectra of BCT solutions (Ba-Ca-Ti-CA) do not exhibit non-ionized carboxylic groups in the region near $1720 \mathrm{~cm}^{-1}$. This occurs because at $\mathrm{pH} \approx 8$, all carboxyl groups present are ionized [21]. In the infrared spectrum of barium calcium titanate, two bands are observed, both with asymmetric and symmetric stretchings. These are attributed to the presence of a metal-CA complex in the BCT with the production of various carboxylic groups $[22,23]$. In all complexes, frequencies of asymmetric and symmetric carbonyl stretchings are located at $1565-1665 \mathrm{~cm}^{-1}$ and $1145-1389 \mathrm{~cm}^{-1}$, respectively. The difference between asymmetric $\left(v_{\text {as }}\right)$ and symmetrical $\left(v_{\mathrm{s}}\right)$ stretchings $\left(\Delta\left(v_{\mathrm{as}}-v_{\mathrm{s}}\right)\right)$ of the $\mathrm{COO}^{-}$carbonyl group varies within the range of $176-220 \mathrm{~cm}^{-1}$, suggesting that the carboxylic groups 


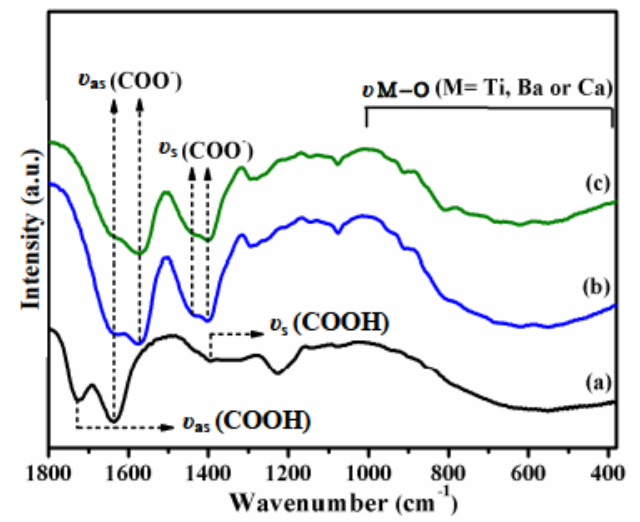

Fig. 1 Absorption spectra in the infrared region of precursor solutions: (a) $\mathrm{TC}$, (b) $\mathrm{CaCO}_{3}$ and $\mathrm{BaCO}_{3}$, and (c) $\mathrm{Ba}_{0.8} \mathrm{Ca}_{0.2} \mathrm{CO}_{3}$.

show complexes with unidentate coordination [22,23]. If the carboxylic groups are involved in a chelation bridge of the complex with $\mathrm{CA}, \Delta\left(v_{\mathrm{as}}-v_{\mathrm{s}}\right) \approx 170 \mathrm{~cm}^{-1}$ would be expected. Characteristic peaks of free CA are observed in the region below $1000 \mathrm{~cm}^{-1}$, which disappear after CA chelation, giving rise to a broad band attributed to the $\mathrm{M}-\mathrm{O}$ stretching, where $\mathrm{M}=\mathrm{Ti}$, $\mathrm{Ba}$ or $\mathrm{Ca}$ [24]. This analysis suggests that both starting materials could be used to obtain the precursor solution of $\mathrm{Ba}_{0.8} \mathrm{Ca}_{0.2} \mathrm{TiO}_{3}$ polymer resins $[21,25]$.

TG/DTA analyses shown in Fig. 2 are performed on the resins after heat treatment at $300{ }^{\circ} \mathrm{C}$ for $4 \mathrm{~h}$. The obtained curves for both starting materials show similar behavior. TG analysis (Fig. 2(a)) indicates four stages. The first stage $\left(25-120^{\circ} \mathrm{C}\right)$ shows mass loss attributed to the removal of water and excess ethylene glycol. From $120{ }^{\circ} \mathrm{C}$ to $480{ }^{\circ} \mathrm{C}$, the highest mass loss is observed, which is attributed to the decomposition of the polymer chain and removal of $\mathrm{CO}_{2}$ and $\mathrm{H}_{2} \mathrm{O}$. The third stage occurs from $480{ }^{\circ} \mathrm{C}$ to $558{ }^{\circ} \mathrm{C}$ and corresponds to the formation of an intermediate phase called barium oxycarbonate $\left(\left(\mathrm{Ba}_{0.8} \mathrm{Ca}_{0.2}\right)_{2} \mathrm{Ti}_{2} \mathrm{O}_{5} \cdot \mathrm{CO}_{3}\right)$ [26]. From $558{ }^{\circ} \mathrm{C}$ to $675{ }^{\circ} \mathrm{C}$, there are decomposition of this phase with mass loss of approximately $3 \%$ and subsequently the formation of crystalline $\mathrm{Ba}_{0.8} \mathrm{Ca}_{0.2} \mathrm{TiO}_{3}$. No mass loss is observed above $675{ }^{\circ} \mathrm{C}$ [26,27].

DTA curves (Fig. 2(b)) show the presence of an exothermic peak around $450{ }^{\circ} \mathrm{C}$, which is attributed to the rupture of the polymer chain. A small weight loss from $500{ }^{\circ} \mathrm{C}$ is observed in the TG/DTA curves, suggesting the beginning of the crystallization process. However, the presence of two low-intensity exothermic peaks at $520{ }^{\circ} \mathrm{C}$ and $650{ }^{\circ} \mathrm{C}$, respectively, indicates the
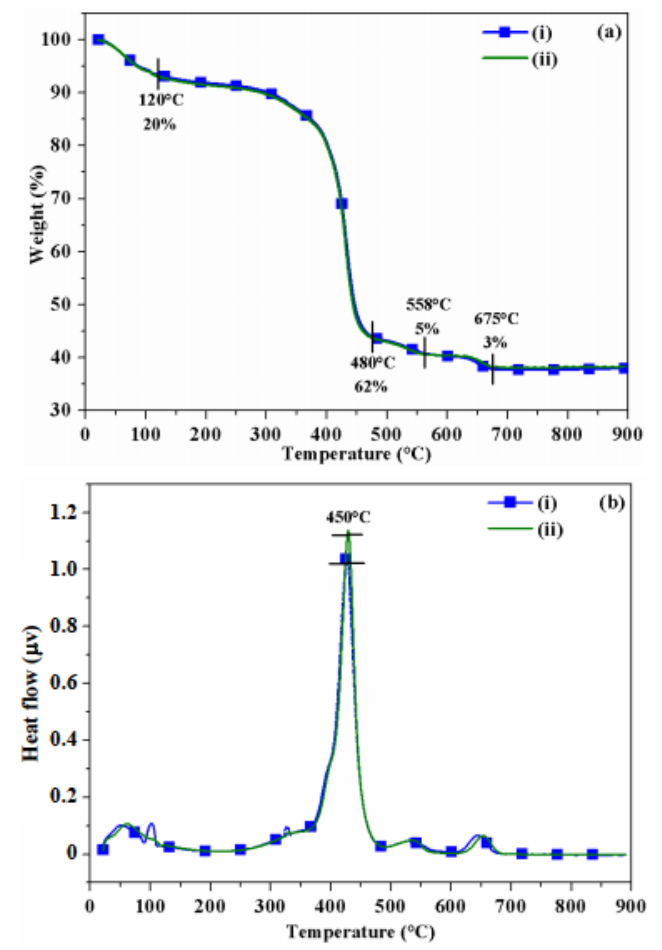

Fig. 2 (a) TG and (b) DTA of pre-pyrolyzed BCT powders with the starting reagents: (i) $\mathrm{CaCO}_{3}$ and $\mathrm{BaCO}_{3}$, (ii) $\mathrm{Ba}_{0.8} \mathrm{Ca}_{0.2} \mathrm{CO}_{3}$.

formation and decomposition of intermediate phases, such as barium calcium carbonate [28].

The thermal evolution of the $\mathrm{Ba}_{0.8} \mathrm{Ca}_{0.2} \mathrm{TiO}_{3}$ phase is investigated by XRD and Raman spectroscopy in the samples calcined at different temperatures $\left(400-700{ }^{\circ} \mathrm{C}\right)$ and time (1-8h). Figure 3 illustrates the XRD patterns of the samples treated at $700{ }^{\circ} \mathrm{C}$ for $4 \mathrm{~h}$ using both starting materials. Tetragonal perovskite-type $\mathrm{BaTiO}_{3}$ (ICSD No. 95436) is present in all samples. No secondary phase peaks are found.

Figure 4 presents a time-temperaturetransformation (TTT) phase diagram constructed from

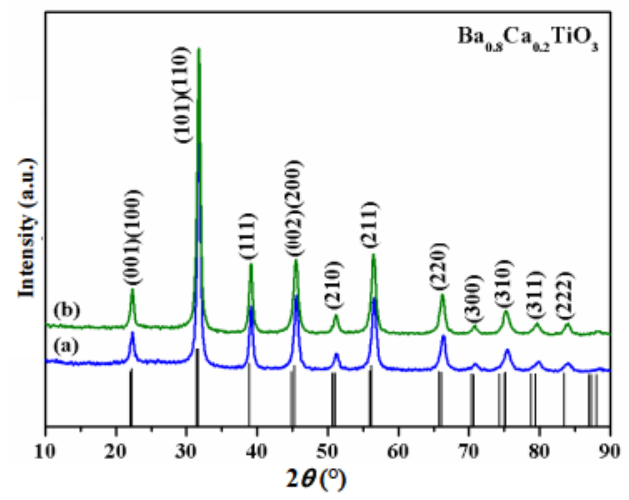

Fig. 3 X-ray diffractograms of $\mathrm{BCT}$ powders calcined at $700{ }^{\circ} \mathrm{C}$ for $4 \mathrm{~h}$ prepared using: (a) $\mathrm{CaCO}_{3}$ and $\mathrm{BaCO}_{3}$, (b) $\mathrm{Ba}_{0.8} \mathrm{Ca}_{0.2} \mathrm{CO}_{3}$. 


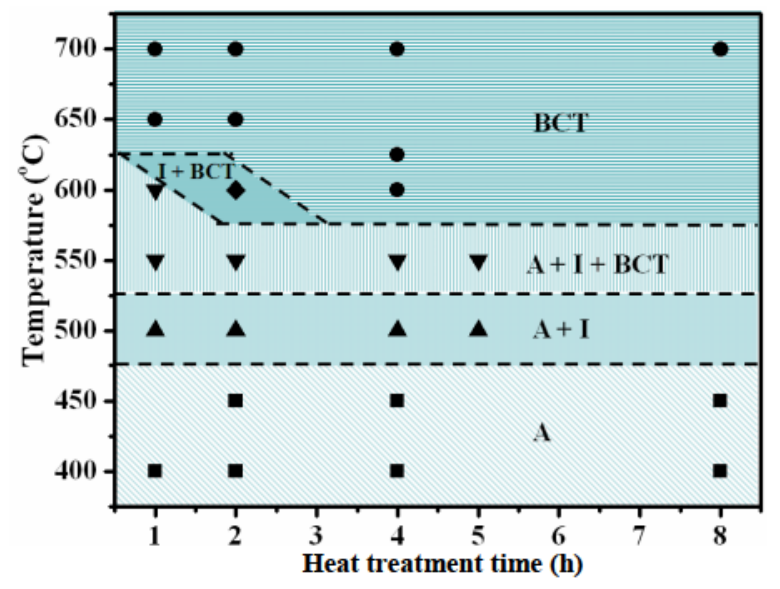

Fig. 4 Time-temperature-transformation (TTT) diagram and evolution of the $\mathrm{BCT}$ crystalline phase obtained from different starting materials ( $\mathrm{A}=$ disordered, $\mathrm{I}=$ $\left(\mathrm{Ba}_{0.8} \mathrm{Ca}_{0.2}\right)_{2} \mathrm{Ti}_{2} \mathrm{O}_{5} \cdot \mathrm{CO}_{3}$ and $\left.\mathrm{BCT}=\mathrm{Ba}_{0.8} \mathrm{Ca}_{0.2} \mathrm{TiO}_{3}\right)$.

XRD results of BCT samples obtained with different starting materials (since the results are similar, only one figure is presented for simplicity). The diagram shows that within $8 \mathrm{~h}$ treatment at $400{ }^{\circ} \mathrm{C}$, all samples remain disordered. At $500{ }^{\circ} \mathrm{C}$, the formation of the intermediate phase $\left(\mathrm{Ba}_{0.8} \mathrm{Ca}_{0.2}\right)_{2} \mathrm{Ti}_{2} \mathrm{O}_{5} \cdot \mathrm{CO}_{3}$ could be observed. Around $600{ }^{\circ} \mathrm{C}$ and after $2 \mathrm{~h}$ of thermal treatment, the intermediate layer is decomposed and the BCT phase is obtained. These results show that $\mathrm{Ba}_{0.8} \mathrm{Ca}_{0.2} \mathrm{TiO}_{3}$ prepared with both starting reagents shows a similarity in the evolution of the formation of the crystalline phase with respect to the increasing temperature.

Figure 5 illustrates the Raman spectra of powders calcined at $700{ }^{\circ} \mathrm{C}$ for both starting materials. The Raman active modes for $\mathrm{BaTiO}_{3}$ with tetragonal structure $(P 4 m m)$ are $4 \mathrm{E}(\mathrm{TO}+\mathrm{LO})+3 \mathrm{~A}_{1}(\mathrm{TO}+\mathrm{LO})+$ $1 \mathrm{~B}_{1}(\mathrm{TO}+\mathrm{LO})$. The peak intensity at about $303 \mathrm{~cm}^{-1}$ is given by the overlap of modes $\mathrm{E}(3 \mathrm{TO})+\mathrm{E}(2 \mathrm{LO})+\mathrm{B}_{1}$. This vibrational mode is characteristic of a tetragonal structure; therefore, an increase in the symmetry of the network tends to disappear in this peak. The band at $640 \mathrm{~cm}^{-1}$ is attributed to the hexagonal phase of $\mathrm{BaTiO}_{3}$. However, Cho [29] reported that this hexagonal phase is the result of particles with defects on plane (111). These defects can generate satellite peaks that correspond to the hexagonal phase in the Raman effect. The spectra for the powders show the appearance of three characteristic bands of the tetragonal structure at $724 \mathrm{~cm}^{-1}, 523 \mathrm{~cm}^{-1}$ and $263 \mathrm{~cm}^{-1}$. It can be seen that the use of different starting materials for the synthesis of BCT does not result in changes in the Raman spectra.

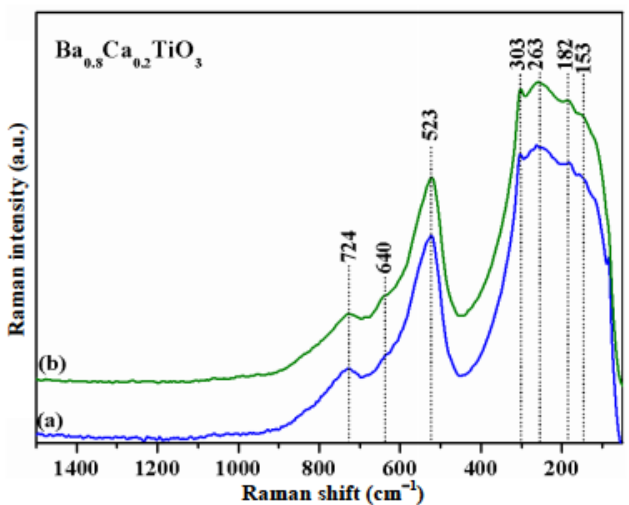

Fig. 5 Raman spectra obtained for BCT powders calcined at $700{ }^{\circ} \mathrm{C}$ for $4 \mathrm{~h}$ using: (a) $\mathrm{CaCO}_{3}$ and $\mathrm{BaCO}_{3}$, (b) $\mathrm{Ba}_{0.8} \mathrm{Ca}_{0.2} \mathrm{CO}_{3}$

By means of field emission scanning electron microscopy (FE-SEM) analysis performed for both materials, it is verified that the materials synthesized from titanium citrate, $\mathrm{CaCO}_{3}$ and $\mathrm{BaCO}_{3}$ (Fig. 6(a)) and from titanium citrate and $\mathrm{Ba}_{1-x} \mathrm{Ca}_{x} \mathrm{CO}_{3}$ solid solution (Fig. 6(b)) are composed of several agglomerated particles without the presence of well-defined morphology.
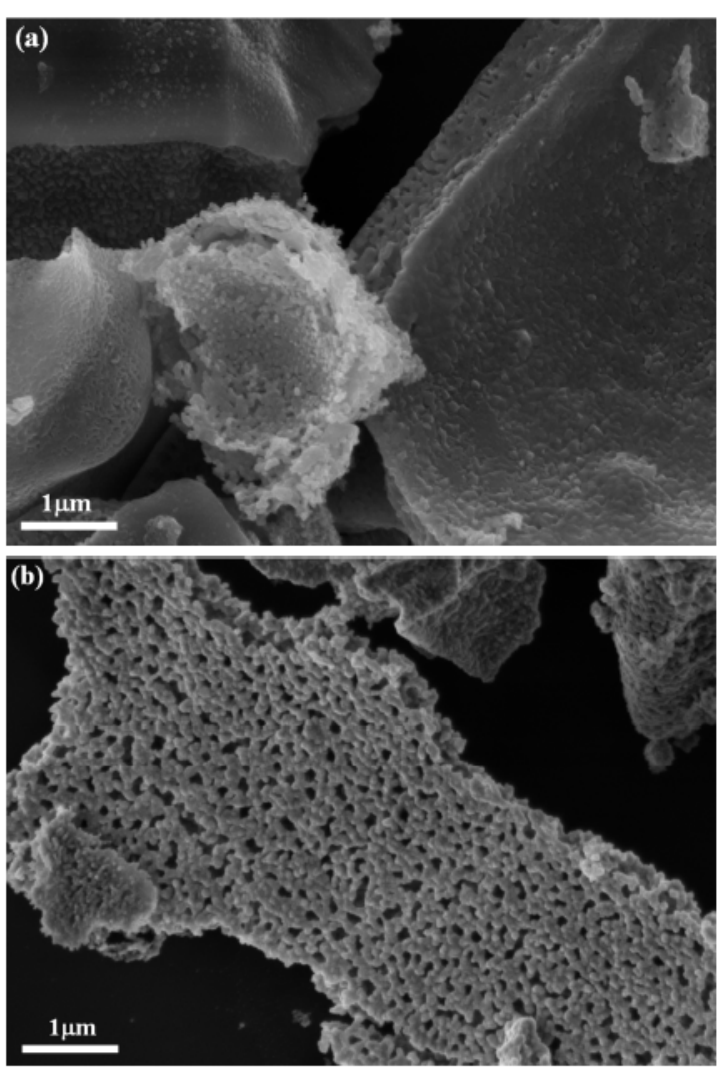

Fig. 6 FE-SEM images of the powders synthesized with different starting reagents: (a) $\mathrm{CaCO}_{3}$ and $\mathrm{BaCO}_{3}$, (b) $\mathrm{Ba}_{1-x} \mathrm{Ca}_{x} \mathrm{CO}_{3}$. 
According to the literature, due to the large amount of organic material, the polymeric precursor method needs to eliminate it for the synthesis of pure oxides, but may result in the formation of agglomerates especially after sintering [30]. It should also be taken into account the high reactivity of the particles along with the organic material, which facilitates the emergence of highly agglomerated morphologies [31].

Thus, powders submitted to $700{ }^{\circ} \mathrm{C}$ for $4 \mathrm{~h}$ for sintering result in the formation of agglomerated regions. There are no significant differences in their morphologies, which are possible to observe for both starting reagents.

\section{Conclusions}

$\mathrm{Ba}_{0.8} \mathrm{Ca}_{0.2} \mathrm{TiO}_{3}$ (BCT) obtained using different starting reagents showed a similar chelation of $\mathrm{Ba}-\mathrm{Ca}-\mathrm{Ti}-\mathrm{CA}$ ions for both sets and few differences were observed during thermal evolution study. BCT powders showed no structural differences as obtained from $\mathrm{CaCO}_{3}$ and $\mathrm{BaCO}_{3}$ or $\mathrm{Ba}_{0.8} \mathrm{Ca}_{0.2} \mathrm{CO}_{3}$. This preliminary study showed that the synthesis of $\mathrm{Ba}_{0.8} \mathrm{Ca}_{0.2} \mathrm{TiO}_{3}$ obtained by complex polymerization method was effective for all starting materials. Synthesis with individual carbonates $\left(\mathrm{CaCO}_{3}\right.$ and $\left.\mathrm{BaCO}_{3}\right)$ involved fewer steps since only one synthesis was necessary to obtain $\mathrm{BCT}$, thereby showing advantages in comparison to the synthesis using $\mathrm{Ba}_{0.8} \mathrm{Ca}_{0.2} \mathrm{CO}_{3}$ solid solution as precursor.

\section{Acknowledgements}

The authors thank the financial support of the Brazilian research financing institutions: CNPq, CAPES and FAPESP-CDMF 2013/07296-2.

Open Access: This article is distributed under the terms of the Creative Commons Attribution License which permits any use, distribution, and reproduction in any medium, provided the original author(s) and the source are credited.

\section{References}

[1] Motta FV, Marques APA, Espinosa JWM, et al. Room temperature photoluminescence of $\mathrm{BCT}$ prepared by complex polymerization method. Curr Appl Phys 2010, 10: $16-20$.

[2] Ctibor P, Sedlacek J. Selected aspects of dielectric behavior of plasma sprayed titanates. J Adv Ceram 2012, 1: 50-59.

[3] Praveen JP, Kumar K, James AR, et al. Large piezoelectric strain observed in sol-gel derived BZT-BCT ceramics. Curr Appl Phys 2014, 14: 396-402.

[4] Devi S, Jha AK. Tungsten substituted barium titanate: Effect of heating rate on the microstructural, dielectric and ferroelectric properties. Curr Appl Phys 2011, 11: S95-S99.

[5] Park J-S, Lee Y-H, Kim K-B, et al. Structural study of Ca doped barium titanate. Nucl Instrum Meth B 2012, 284: 44-48.

[6] Puli VS, Pradhan DK, Riggs BC, et al. Investigations on structure, ferroelectric, piezoelectric and energy storage properties of barium calcium titanate (BCT) ceramics. J Alloys Compd 2014, 584: 369-373.

[7] Mitsui T, Westphal WB. Dielectric and X-ray studies of $\mathrm{Ca}_{x} \mathrm{Ba}_{1-x} \mathrm{TiO}_{3}$ and $\mathrm{Ca}_{x} \mathrm{Sr}_{1-x} \mathrm{TiO}_{3}$. Phys Rev 1961, 124: 1354 .

[8] Zhang L, Thakur OP, Feteira A, et al. Comment on the use of calcium as a dopant in $\mathrm{X} 8 \mathrm{R} \mathrm{BaTiO}_{3}$-based caramics. Appl Phys Lett 2007, 90: 142914.

[9] Rai AK, Rao KN, Kumar LV, et al. Synthesis and characterization of ultra fine barium calcium titanate, barium strontium titanate and $\mathrm{Ba}_{1-2 x} \mathrm{Ca}_{x} \mathrm{Sr}_{x} \mathrm{TiO}_{3}(x=0.05$, 0.10). J Alloys Compd 2009, 475: 316-320.

[10] Araújo VD, Motta FV, Marques APA, et al. Effect of calcium on the structural properties of $\mathrm{Ba}_{(1-x)} \mathrm{Ca}_{x} \mathrm{TiO}_{3}$ particles synthesized by complex polymerization method. J Mater Sci 2014, 49: 2875-2878.

[11] Lee JH, Won CW, Kim TS, et al. Characteristics of $\mathrm{BaTiO}_{3}$ powders synthesized by hydrothermal process. J Mater Sci 2000, 35: 4271-4274.

[12] Ciftci E, Rahaman MN, Shumsky M. Hydrothermal precipitation and characterization of nanocrystalline $\mathrm{BaTiO}_{3}$ particles. J Mater Sci 2001, 36: 4875-4882.

[13] Zhu W, Wang CC, Akbar SA, et al. Fast-sintering of hydrothermally synthesized $\mathrm{BaTiO}_{3}$ powders and their dielectric properties. J Mater Sci 1997, 32: 4303-4307.

[14] Takeuchi T, Suyama Y, Sinclair DC, et al. Spark-plasmasintering of fine $\mathrm{BaTiO}_{3}$ powder prepared by a sol-crystal method. J Mater Sci 2001, 36: 2329-2334.

[15] Jayanthi S, Kutty TRN. Extended phase homogeneity and electrical properties of barium calcium titanate prepared by the wet chemical methods. Mat Sci Eng B 2004, 110: 202-212.

[16] Zhang W, Shen Z, Chen J. Preparation and characterization of nanosized barium calcium titanate crystallites by low temperature direct synthesis. J Mater Sci 2006, 41: 5743-5745.

[17] Tiwari VS, Pandey D, Groves P. The influence of a powder processing technique on chemical homogeneity and the diffuse phase transition behaviour of $\mathrm{Ba}_{0.9} \mathrm{Ca}_{0.1} \mathrm{TiO}_{3}$ ceramics. J Phys D: Appl Phys 1989, 22: 837.

[18] Tiwari VS, Singh N, Pandey, D. Structure and properties of $(\mathrm{Ba}, \mathrm{Ca}) \mathrm{TiO}_{3}$ ceramics prepared using $(\mathrm{Ba}, \mathrm{Ca}) \mathrm{TiO}_{3}$ ceramics: I, Crystallographic and microstructural studies. J Am Ceram Soc 1994, 77: 1813-1818

[19] Tiwari VS, Pandey D. Structure and properties of $(\mathrm{Ba}, \mathrm{Ca}) \mathrm{TiO}_{3}$ ceramics prepared using $(\mathrm{Ba}, \mathrm{Ca}) \mathrm{CO}_{3}$ 
precursors: II, Diffuse phase transition behavior. $J \mathrm{Am}$ Ceram Soc 1994, 77: 1819-1824.

[20] Motta FV, Marques APA, Escote MT, et al. Preparation and characterizations of $\mathrm{Ba}_{0.8} \mathrm{Ca}_{0.2} \mathrm{TiO}_{3}$ by complex polymerization method (CPM). J Alloys Compd 2008, 465 : 452-457.

[21] Fang T-T, Tsay J-D. Effect of pH on the chemistry of the barium titanium citrate gel and its thermal decomposition behavior. J Am Ceram Soc 2001, 84: 2475-2478.

[22] Rajendran M, Rao MS. Formation of $\mathrm{BaTiO}_{3}$ from citrate precursor. J Solid State Chem 1994, 113: 239-247.

[23] Yasodhai S, Sivakumar T, Govindarajan S. Preparation, characterization and thermal reactivity of transition metal complexes of hydrazine with citric acid. Thermochim Acta 1999, 338: 57-65.

[24] Durán P, Gutierrez D, Tartaj J, et al. On the formation of an oxycarbonate intermediate phase in the synthesis of $\mathrm{BaTiO}_{3}$ from (Ba,Ti)-polymeric organic precursors. $J$ Eur Ceram Soc 2002, 22: 797-807.

[25] Kakihana M, Arima M, Nakamura Y, et al. Spectroscopic characterization of precursors used in the Pechini-type polymerizable complex processing of barium titanate.
Chem Mater 1999, 11: 438-450.

[26] Kumar S, Messing GL. Metal organic resin derived barium titanate: II, Kinetics of $\mathrm{BaTiO}_{3}$ formation. $\mathrm{J} \mathrm{Am}$ Ceram Soc 1994, 77: 2940-2948.

[27] Vinothini V, Singh P, Balasubramaniam M. Synthesis of barium titanate nanopowder using polymeric precursor method. Ceram Int 2006, 32: 99-103.

[28] Gablenz S, Abicht HP, Pippel E, et al. New evidence for an oxycarbonate phase as an intermediate step in $\mathrm{BaTiO}_{3}$ preparation. JEur Ceram Soc 2000, 20: 1053-1060.

[29] Cho W-S. Structural evolution and characterization of $\mathrm{BaTiO}_{3}$ nanoparticles synthesized from polymeric precursor. J Phys Chem Solids 1998, 59: 659-666.

[30] Lopes KP, Cavalcante LS, Simões AZ, et al. $\mathrm{NiTiO}_{3}$ powders obtained by polymeric precursor method: Synthesis and characterization. $J$ Alloys Compd 2009, 468: 327-332.

[31] Leal SH, Sczancoski JC, Cavalcante LS, et al. Structural and morphological characteristics of $\left(\mathrm{Pb}_{1-\mathrm{x}} \mathrm{Sr}_{\mathrm{x}}\right) \mathrm{TiO}_{3}$ powders obtained by polymeric precursor method. J Sol-Gel Sci Technol 2010, 53: 21-29. 